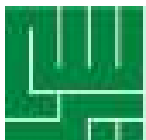

\title{
Proportion of Diabetes Mellitus in Koja General Hospital
}

\author{
Suzanna Ndraha, Hervico Dwicahya Putra, \\ Caesaredo Derza Polas, Ratih Laura Sabrina, \\ Khairul Hud:: \\ Department of Internal Medicine, Koja Hospital, Jakarta
}

\begin{abstract}
KEYWORDS
ABSTRACT

Koja General Hospital, Diabetes Mellitus (DM), proportion

Diabetes mellitus (DM) is one of the most common disease found in clinical practice in Koja General Hospital. According to the previous research, the prevalence of diabetes patients has never been investigated. Aim of this study was to find out the proportion of diabetes subjects hospitalized in Koja General Hospital.

This was a descriptive study with a cross sectional approach. Data was taken by consecutive sampling method from diabetes mellitus subjects aged $\geq 18$ years who were hospitalized in the department of internal medicine Koja General Hospital in the period of August 20, until September 30, 2018.

The proportion of diabetes subjects in Koja General Hospital was $42 \%$ (155 patients) out of a total of 368 subjects. The age of diabetes subjects with the majority of elderly adults (26-65 years) as much as $84 \%$ (131 patients) of 155 diabetes subjects. Gender were dominated by woman as 59\% (91 patients) out of a total of 155 subjects and the remaining men were $41 \%$ (64 patients). The most frequent indication of treatment in diabetes subjects is chronic kidney failure (CKD) as much as 22 patients (14.2\%).

The proportion of diabetes subjects who were hospitalized was $42 \%$ (155 people) of a total of 368 subjects.
\end{abstract}

\section{INTRODUCTION}

Diabetes mellitus is a heterogeneous metabolic disorder characterized by the presence of hyperglycemia due to impairment of insulin secretion, defective insulin action or both. The chronic hyperglycemia of diabetes is associated with relatively specific long- term microvascular complications affecting the eyes, kidneys and nerves, as well as an increased risk for cardiovascular disease (CVD).

Correspondence:

Suzanna Ndraha, Department of Internal Medicine, Koja Hospital, Jakarta 
The diagnostic criteria for diabetes are based on thresholds of glycemia that are associated with microvascular disease, especially retinopathy (Punthakee $\mathrm{Z}$ et al., 2018). Type 2 diabetes, previously referred to as "noninsulin-dependent diabetes" or "adult-onset diabetes," accounts for 90$95 \%$ of all diabetes. This form encompasses individuals who have relative (rather than absolute) insulin deficiency and have peripheral insulin resistance. At least initially, and often throughout their lifetime, these individuals may not need insulin treatment to survive.

The risk of developing type 2 diabetes increases with age, obesity, and lack of physical activity. It occurs more frequently in women with prior Gestational Diabetes Mellitus, in those with hypertension or dyslipidemia, and in certain racial/ethnic subgroups (African American, American Indian, Hispanic/Latino, and Asian American). It is often associated with a strong genetic predisposition or family history in first- degree relatives, more so than type 1 diabetes (American Diabetes Association 2018). Uncontrolled diabetes, refers to glucose levels that exceed the target limit and results in immediate short-term effects (dehydration, body weight reduction, blurred vision, hunger) and long term damage to micro and macro blood vessels (Subekti I dkk. 2012). In Indonesia, Riset Kesehatan Dasar (Riskesdas) data shows that there is an increase in the prevalence of diabetes in Indonesia from $5.7 \%$ in 2007 to $6.9 \%$ or around 9.1 million in 2013.

The International Diabetes Federation data in 2015 states that the estimation number of people with diabetes in Indonesia is about 10 million.
The world condition's today as well, diabetes is now one of the biggest causes of death in Indonesia. Data Sample Registration Survey in 2014 showed that diabetes was the third largest cause of death in Indonesia with a percentage of $6.7 \%$, after stroke $(21.1 \%)$ and coronary heart disease $(12.9 \%)$. If not addressed, this condition can lead to a decrease in productivity, disability, and premature death (Departemen Kesehatan Republik Indonesia 2016). In Koja General Hospital, diabetes mellitus is one of the most frequent cases found in medical ward. The aim of the present study was to estimate the proportion of diabetes mellitus in internal medicine ward as well as the clinical profile of diabetes mellitus in Koja General Hospital

\section{METHOD}

This was a descriptive study with a cross sectional approach. Data was taken by consecutive sampling method from diabetes mellitus subjects aged more than 18 years who were hospitalized in the ward of internal medicine Koja General Hospital in the period of August 20, 2018 to September 30,2018 . The inclusion criteria were all subjects with a diagnosis of diabetes mellitus who are hospitalized in the internal medicine ward. Subjects would be excluded if the age less than 18 years. Data collection was perform using the research forms. Data analysis using SPSS, to find out the proportion of DM subjects during the study period. All the data was recorded in the entry form, and further organized using descriptive statistics, presented as mean \pm SD for numerical data, and $\mathrm{n}(\%)$ for the categorical data. 
RESULTS

Total of 368 patients admitted and seen in internal medicine at Koja General Hospital from August 20, 2018 to September 30, 2018. Results were described in Table 1 and figure 1. One hundred and fifty-five patients (42\%) were diabetes mellitus, most of the subjects were female, as well as most in 25-62 years old age group.

Table 1. Baseline characteristics of diabetic patients $(n=155)$

\begin{tabular}{lc}
\hline \multicolumn{1}{c}{ Characteristic } & $\mathrm{N}(\%)$ \\
\hline Gender & $64(41)$ \\
Male & $91(59)$ \\
Female & \\
Age & $3(2)$ \\
18-25 years old & $131(89)$ \\
26-65 years old & $14(9)$ \\
>65 years old & \\
Indication of hospitalization & 24 \\
Chronic kidney disease & 19 \\
Diabetic ulcer & 14 \\
Hypoglycemia & 12 \\
Anemia & 10 \\
Urinary tract infection & 10 \\
Pulmonary tuberculosis & 9 \\
Heart failure & 8 \\
Uncontrolled hypertension & 8 \\
Bacterial infection & 8 \\
Pneumonia & 7 \\
Dyspepsia & 7 \\
Hemiparesis & 7 \\
HIV -AIDS & 12 \\
Others &
\end{tabular}

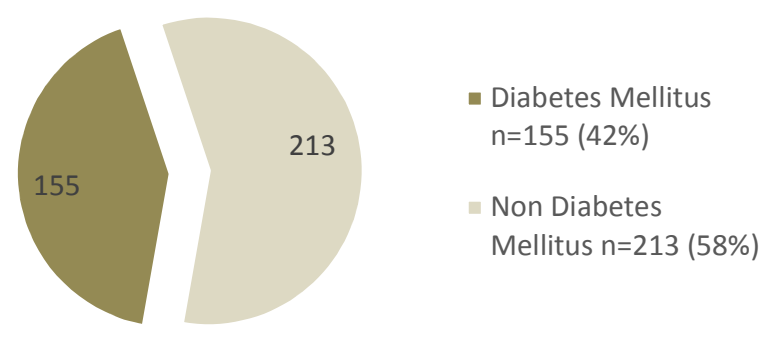

Figure 1. Proportion of DM Subject $(n=368)$ 
As for the age profile, the most subjects were old adult (26-65 years) with 131 patients $(89 \%)$ of a total of 155 subjects, followed by elderly ( $>65$ years) of 21 patients $(14 \%)$ and young adult (18-25 years) as many as 3 patients $(2 \%)$ (Figure 2).

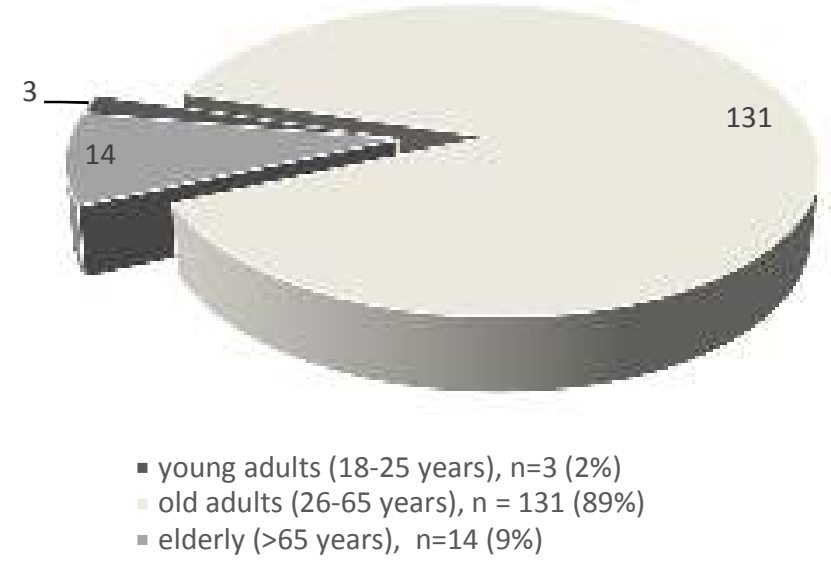

Figure 2. Age distribution of Diabetes Mellitus $(n=155)$

Diabetes mellitus subjects were the remaining male were $41 \%$ (64 dominated by female as much as 59\% people) (Figure 3).

(91 patients) of a total of 155 subjects and

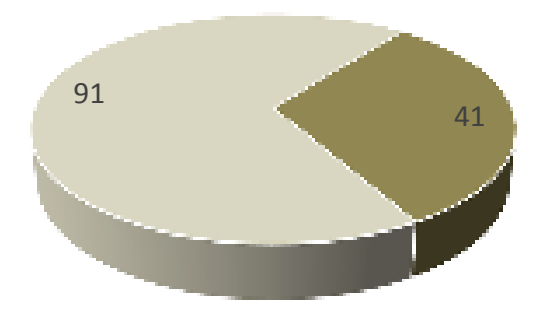

- Female $n=91(59 \%) \quad$ - Male $n=41(64 \%)$

Figure 3. Distribution of gender of Diabetes Mellitus ( $n=155)$

The most common indication for hospitalization was chronic kidney disease $(n=24,15.5 \%)$ followed by diabetic ulcer 19 patients (12.2\%), hypoglycemia 14 patients (9\%), anemia
12 patients $(7.7 \%)$, urinary tract infection and pulmonary tuberculosis 10 patients $(6.5 \%)$ respectively, heart failure 9 patients (5.8\%), uncontrolled hypertension, bacterial infection and 
pneumonia 8 patients $(5.2 \%)$ respectively, dyspepsia, hemiparesis and HIV-AIDS 7 patients $(4.5 \%)$ respectively, electrolyte imbalance 6 patients $(3.9 \%)$ and the remaining 6 patients $(3.9 \%)$ were hospitalized due to other causes such as preparation of surgery and endoscopic examination.

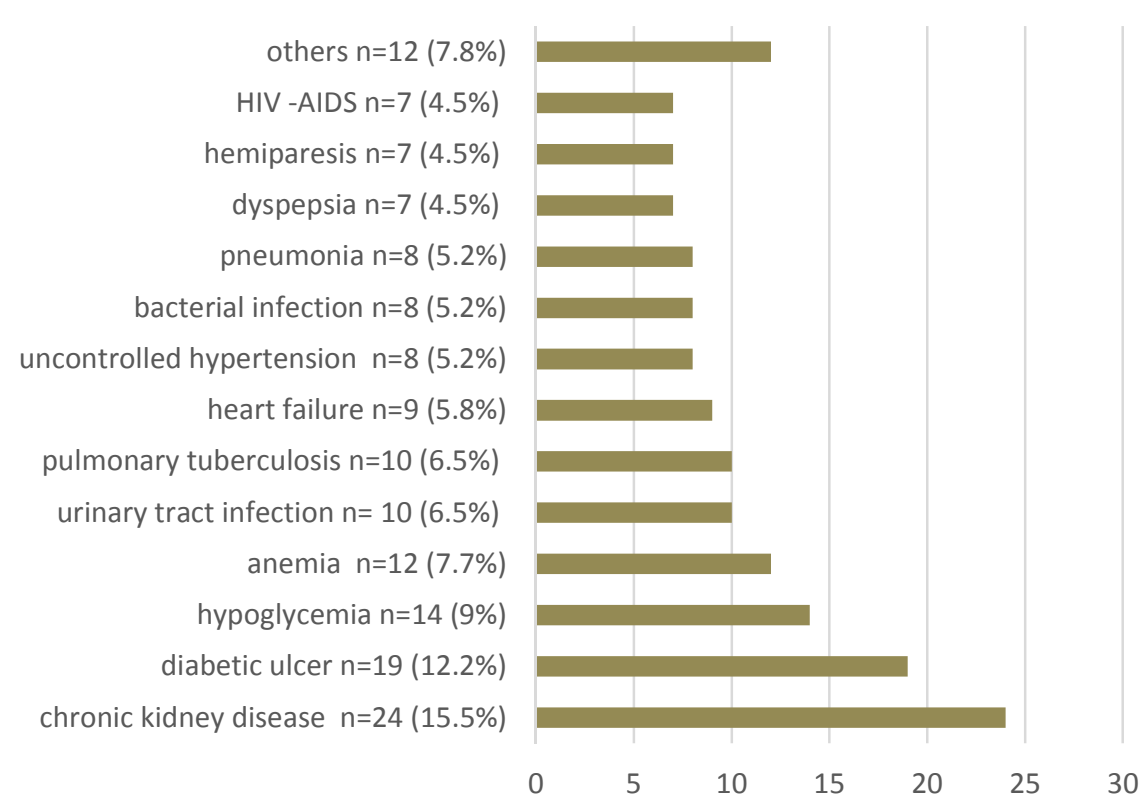

Figure 4. Indications for hospitalization $(\mathrm{n}=155)$

\section{DISCUSSION}

Kufeldt et al (2018) found that every fourth patient in the university hospital in Germany had diabetes and every second had either prediabetes or diabetes. It is also worthwhile to screen for unknown diabetes in patients over the age of 50. This is higher than in UK whereas the 2016 National Diabetes Inpatient Audit suggested that the prevalence of diabetes amongst inpatients had risen from $15 \%$ in 2010 to 17\% in 2016 (Corsino L et al., 2017). In US study, the prevalence of diabetes in hospitalized adults aged 65-75 years and over 80 years of age has been estimated to be $20 \%$ and $40 \%$, respectively (Umpierrez GE, Pasquel FJ 2017). In this present study, the proportion of diabetes among inpatients reached $42 \%$ of a total of 368 subjects. Our study finding was in line with data in Germany, UK and US.

Age distribution of diabetes subjects in this study was dominated by aged $26-65$ years $(89 \%)$, while in elderly population it was 9\%. In Korean population the age-standardized prevalence of diabetes in the elderly population aged $\geq 60$ years showed prevalence $24.7 \%$ in 2014 . The prevalence of diabetes in the elderly population in Korea is higher than our study (Kook BK and Moon BK 2001).

Fifty percent subject in this study was female (figure 3), showed domination of female gender in our population. This finding was not in accordance with data from National 
Diabetes Statistics Report, 2017 the United States that showed similar number in both gender.

Whereas for indications of diabetes patient care can be seen for various reasons, but chronic kidney disease $(\mathrm{CKD})$ is the most frequent indication of treatment in subjects with diabetes. This is because one of the most common complications in people with diabetes is CKD, this is in line with what was stated by Philips and friends (2018). Then followed by diabetes foot as an indication of the most treatment. In subjects with uncontrolled sugar levels for a long time, diabetes foot is a complication that is widely seen, especially in developing countries such as Indonesia. Hypoglycemia is in the third order indicative of diabetes patient care. In a study conducted by Wung and his colleagues (2011), placing hypoglycemia as one of the most common causes of diabetes subjects came in the ER.

\section{CONCLUSION}

The proportion of diabetes among inpatients reached $42 \%$ of a total of 368 subjects. Majority of the total subjects with diabetes in Koja General Hospital who were hospitalized in the study time are dominant in older adult age (26-65 years) with the highest gender, mostly women. Most subjects are admitted to care with indications of uncontrolled complications of diabetes mellitus.

\section{REFERENCES}

American Diabetes Association 2018. Classification and Diagnosis of Diabetes: Standards of Medical Care in Diabetes-2018. Diabetes Care 2018 Jan; 41(Supplement 1): S13-S27.
Available from https://doi.org/10.2337/dc18-S002. Corsino L, Dhatariya K, Umpierrez G 2017. Management of Diabetes and Hyperglycemia in Hospitalized Patients. [Updated 2017 Oct 1]. In: De Groot LJ, Chrousos G, Dungan K, et al., editors. Endotext [Internet]. South Dartmouth (MA): MDText.com, Inc.; 2000. Available from: https://www.ncbi.nlm.nih.gov/books /NBK279093/.

Departemen Kesehatan Republik Indonesia 2016. Laporan Hasil Riset Kesehatan Dasar Indonesia tahun 2016. Jakarta : Badan Penelitian dan Pengembangan Kesehatan Depkes RI; 2016.

Koo BK, Moon MK 2016. Are We in the Same Risk of Diabetes Mellitus? Gender- and Age-Specific Epidemiology of Diabetes in 2001 to 2014 in the Korean Population. Diabetes Metab J. 2016 Jun; 40(3): 175181. doi: [10.4093/dmj.2016.40.3.175] Available from: https://www.ncbi.nlm.nih.gov/pmc/ articles/PMC4929220/

Kufeldt J, Kovarova M, Adolph M, Staiger $\mathrm{H}$, Bamberg $\mathrm{M}$, Häring HU, Fritsche A, Peter A 2017. Prevalence and Distribution of Diabetes Mellitus in a Maximum Care Hospital: Urgent Need for HbA1c-Screening. Exp Clin Endocrinol Diabetes. 2018 Feb;126(2):123-129. doi: 10.1055/s-0043112653. Epub 2017 Jul 27. Available from:

https://www.ncbi.nlm.nih.gov/pubm ed/28750430.

National Diabetes Statistics Report 2017 Estimates of Diabetes and Its Burden in the United States. Available from: http://www.diabetes.org/assets/pdfs /basics/cdc-statistics-report-2017.pdf.

Philips, et al 2018. Chronic Kidney Disease of Diabetes. Canadian Journal of Diabetes. Canada (2018) p : 5201-5209.

Punthakee Z, Goldenberg R, Katz P Definition, Classification and Diagnosis of Diabetes, Prediabetes and Metabolic Syndrome 2018. Diabetes Canada 
Clinical Practice Guidelines Expert Committee 2018 Clinical Practice Guidelines. Can J Diabetes 42 (2018) S10-S15. Available from url https://doi.org/10.1016/j.jcjd.2017.10. 003.

Subekti I, dkk. 2012. Penatalaksanaan Diabetes Melitus Terpadu. Jakarta 2012 : Balai Penerbit FKUI. 2012 : 245.

Umpierrez GE, Pasquel FJ 2017. Management of Inpatient Hyperglycemia and Diabetes in Older Adults. Diabetes Care 2017 Apr; 40(4): 509517.https://doi.org/10.2337/dc16$0989 . \quad$ Available from: http:// care.diabetesjournals.org/conte nt/40/4/509\#corresp-1.

Wung, et al 2011. Complication of Diabetes on Hospital. Chinese Medical Journal. Guangzhou (2011) p : 21-27. 